\title{
A sociedade brasileira e a sociologia entre dois vírus letais
}

\section{Brazilian society and sociology between two lethal viruses}

\section{Jacob Carlos Lima', Emil Sobottka²}

1. Doutor em Sociologia pela usp (1992), com Pós-doutorado no Department of Urban Studies and Development do Massachusetts Institute of Technology (EUA-2001). Professor Titular no Departamento de Sociologia da UFSCar. Pesquisador do CNPq, foi Coordenador da Área de Sociologia na CAPEs (2011-2014) e de Comitê de Assessoramento da área de Ciências SociaisSociologia do CNPq (2016-2019). É o atual presidente da Sociedade Brasileira de Sociologia (sвs)(2019-2021). https://orcid.org/0000-0001-6475-9575 calimajb@gmail.com

2. Doutor em Sociologia e Ciência Política na área de cooperação internacional não governamental pela Univ. de Muenster (1997). Fez estágios de pósdoutorado com Claus Offe (Univ. Humboldt, 2004-2005), com Hauke Brunkhorst (Univ. Flensburg, 2007-2009) e Axel Honneth (Univ. Frankfurt, 2012). Foi professor visitante nas Universidades de Kassel (2003) e de Göttingen (2017-2018) na Alemanha, na Udelar (2014, 2020) no Uruguai, colaborador da Universidade de Milão. Professor da Pucrs, pesquisador do CNPq e, atual tesoureiro da SBS (2019-2021). Idealizador e editor do periódico Civitas: Revista de Ciências Sociais (2001-2019). https://orcid. org/0000-0001-8615-7305 sobottka@pucrs.br 
Este artigo é um texto de combate, parafraseando Bourdieu. Escrito originalmente para a Sociedade Alemã de Sociologia, teve o objetivo de informar aos colegas europeus, de forma sintética, o contexto sócio-político-sanitário que estamos passando no Brasil. Como tem sido repetido de forma frequente, este país não é para principiantes e entender as atitudes governamentais, o apoio das instituições e de parte da sociedade brasileira ao pandemônio vigente, exige ir além da perplexidade que nos aflige.

O Brasil enfrenta hoje a pandemia da Covid 19, com um governo negacionista que faz com que não haja políticas públicas nacionais de combate ao vírus. O presidente da república faz questão de aparecer em público em aglomerações dizendo que é "uma gripezinha" ou algo sem importância, mesmo com parte da sua equipe tendo pego o vírus e o país ter um número de mortes crescente. Ao lado dele, um ministro da economia com uma proposta de um neoliberalismo que não deu certo em lugar nenhum enfatizando que importa mais preservar economia do que a vida. Juntos, defendem o fim de qualquer isolamento social, na contramão das orientações da Organização Mundial de Saúde (oms) e ignoram a experiência de outros países no combate a pandemia.

Essa posição com relação à pandemia apenas aprofundou outra tragédia anunciada. $\mathrm{O}$ presidente, um ex-militar aposentado aos 33 anos pelo exército brasileiro para assumir o cargo de vereador no Rio de Janeiro, foi parlamentar medíocre por 30 anos e, durante este tempo, caracterizou-se por uma postura de direita tosca, homofóbica, racista, anti-pobre, em um País com uma das maiores desigualdades sociais do mundo. Mesmo com tudo isso, foi eleito em 2019 com o discurso da anti-política, contra o “tudo que está aî”. Se beneficiou de uma crise política-institucional que teve início em 2014 e que culminou com um golpe jurídico-parlamentar em 2016, com o impeachment da então presidente Dilma Rousseff do Partido dos Trabalhadores (РT). Sua campanha contou com o apoio das elites econômicas, corporações jurídicas e militares, da mídia, das igrejas evangélicas, com um forte discurso anti-corrupção se contrapondo ao que seria a "velha política". Sua campanha eleitoral foi caracterizada por forte polarização ideológica anti-PT, marcada pela criminalização seletiva dos setores de esquerda e centro esquerda e por um discurso populista potencializado pela mobilização de redes sociais e multiplicação de fake news. 
$\mathrm{Na}$ ausência de uma proposta política efetiva, seu discurso limitou-se a palavras de ordem (não participou de nenhum debate), na valorização do senso comum e da ignorância e encontrou forte apelo popular. $\mathrm{O}$ anti-intelectualismo, recorrente na história mundial do século xx, foi fortalecido pelo crescimento do fundamentalismo religioso, pautando o debate sobre o criacionismo, o terra-planismo(!) entre outros delírios. O conhecimento científico tornou-se alvo de ironias e foi secundarizado. A Sociologia, as Ciências Sociais a Filosofia e a História, foram eleitas como alvos a serem combatidos em nome de um pretenso e indefinido "marxismo cultural" que estaria minando as bases da família brasileira. Ao assumir o governo, escolheu para sua equipe pessoas ideologicamente próximas, majoritariamente militares, com discursos conspiratórios contra inimigos imaginários (comunistas, ideologias de gênero, vitimismo racial e outros), mas fortemente comprometidas em desmontar o aparato institucional de defesa de direitos e das políticas sociais construídos nas últimas décadas.

Entre as propostas do novo governo e de seus aliados, destacam-se a escola sem partido, com vigilância de salas de aula e denúncias de professores; criminalização de funcionários que falassem mal do governo; recolhimento de livros didáticos considerados "de esquerda". Embora essas propostas tenham sido, até agora, rechaçadas pela justiça, fez numerosas vítimas entre docentes que foram agredidos por alunos ou demitidos de escolas por pretensamente fazerem propaganda ideológica.

O presidente e seu ministro da educação postam seguidamente nas redes sociais ameaças de fechamento de cursos de Sociologia e Filosofia nas universidades públicas (que juntos representam menos de 3\% dos estudantes) e cortes no financiamento de pesquisas no setor. A Sociologia, enquanto disciplina no ensino médio, deixou de ser obrigatória em 2016, como uma espécie de preparação aos ataques que viriam a seguir.

As universidades públicas passaram a ser desmoralizadas pelo então Ministro da Educação como "balbúrdia”, local de orgias sexuais e consumo de drogas. Falsas imagens foram utilizadas, pelo Ministro, para demonstrar como as universidades públicas gastam dinheiro público e não produzem nada. 
$\mathrm{Na}$ Capes, instituição do Ministério da Educação que fomenta e financia a pós graduação no país, foi nomeado em sua presidência um criacionista. As poucas medidas implementadas favorecem a desorganização da pós-graduação e para atender o setor privado, cujas universidades não se destacam, com pouquíssimas exceções, pela qualidade do ensino. $\mathrm{O}$ cNPq, instituição vinculada ao Ministério de Ciência e Tecnologia, que cuida do fomento e dos investimentos em pesquisa anunciou o estabelecimento de áreas prioritárias de pesquisa que excluem as Ciências Sociais e Humanas, assim como o fim de bolsas para estudantes nessas áreas.

O financiamento de pesquisa no Brasil é majoritariamente público e o governo vem reduzindo drasticamente o financiamento do setor em instituições de pesquisa e universidades públicas. As universidades privadas, que respondem por $70 \%$ dos alunos, não fazem pesquisa, com exceção de algumas universidades confessionais. Parte de grupos educacionais são grupos multinacionais que funcionam com ações na bolsa de valores cuja preocupação é atender prioritariamente seus acionistas.

A Covid 19 evidenciou que quase 100\% das pesquisas no país estão nas universidades públicas e estas são fundamentais para o país manter minimamente sua capacidade de resposta aos desafios sanitários do presente. $\mathrm{O}$ Sistema Único de Saúde (sus), politica universal de atendimento, que o novo governo vem tentando desmontar, se mostrou como a única forma possível de enfrentamento, mesmo que precário, da pandemia.

Ao lado disso, o presidente cada vez mais deixa claro seus propósitos autoritários, com a conivência, muitas vezes silenciosa, de outros poderes da república, da mídia e das elites políticas e econômicas. Alegam que o histrionismo do presidente é só de fachada e que os militares, que cada vez mais ocupam o governo, agiriam como poder moderador. O que vemos é o contrário, os militares sustentam o presidente ideologicamente, estando longe de ser o lado racional do governo. Ao contrário, o legitimam.

Inimigos políticos tem sido eliminados nem tão misteriosamente, como no caso da vereadora e socióloga Marielle Franco, no Rio de Janeiro, por milícias armadas com indícios de vinculação à família do presidente. Professores e políticos de oposição têm sido ameaçados. A corrupção, mote do golpe 
jurídico-parlamentar de 2016, evidencia-se como combate seletivo a inimigos políticos. A grilagem de terras na Amazônia e o desmatamento tornou-se política de Estado, com apoio explícito do presidente da república e de seu ministro do meio ambiente. Funcionários do IвAмA, instituto responsável pelo meio ambiente que combate o desmatamento e garimpo ilegais na região, tem sido demitidos. Lideranças indígenas, quilombolas e de trabalhadores rurais, têm sido assassinadas, sem investigação sem grande indignação da mídia e mesmo da sociedade. A oposição está desarticulada, impactada pelo apelo popular que o presidente ainda mantem junto a parte da população que sempre foi excluída, sem acesso a direitos sociais e que, ressentida, se apega a salvadores. Salvadores estes que pregam "direitos sociais ou empregos?" a economia ou a vida?", negam a pandemia e expõe todos a um genocídio.

Temos então duas ameaças virais corroendo o país, uma sanitária, o covid 19; e a outra o chamado bolsonarismo, uma extrema direita no poder que corrói e evidencia as frágeis estruturas ne nossa república e de nossa democracia.

A Sociologia no Brasil sempre enfrentou a desconfiança do poder estabelecido, como ameaça a ser combatida, e foi fortemente reprimida durante a ditadura militar. As sombras da ditatura militar ressurgem, com a volta das comemorações do período ditatorial e idealização de torturadores como heróis; com o fim das comissões de direitos humanos; enfim com a negação da barbárie do período. Mais uma vez a Sociologia se encontra no centro dos ataques que indicam uma escalada contra as liberdades civis e democráticas. Mais uma vez assistimos as instituições civis e do Estado coniventes com os fatos. O século $\mathrm{xx}$ demonstrou os resultados desta conivência. Assistimos um momento descivilizatório como analisado por Elias (2006) no qual vemos a apologia da ignorância e do senso comum.

Muitos tem escritos sobre os cenários futuros pós-pandemia. Como seria a normalização, quais mudanças esperar, e quais as permanências. Schwartz(2020) escrevendo sobre o que seria o "novo normal" destaca o caráter conservador presente tendencialmente na sociedade. Recupera Durkheim para ilustrar que as sociedades tendem mais a busca da estabilidade do que mudanças continuas que desestabilizam a vida social. Com isso tenta relativizar as transformações socioambientais mais desejadas do que vislumbradas no 
horizonte. E ilustra com a gripe espanhola do inicio do século xx que contribuiu para algumas mudanças sanitárias e políticas, mas embora, não se refira as revoluções do período, vale insistir que ocorreram por processos distintos.

Uma consequência já perceptível está na precarização do trabalho. Com a pandemia, cresceu o número de trabalhadores em aplicativos e em home office. As novas tecnologias contribuindo para mudanças no trabalho e mesmo na vida social como um todo, afinal estamos falando também de ensino a distância(EAD), de consultas médicas a distância. Essa precarização não tem inicio com a pandemia, integra o próprio capitalismo e, no Brasil, tem sido implementada a partir de reformas trabalhistas a toque de caixa, como em 2017 e que o atual governo pretende aprofundar. Os trabalhadores de aplicativos, sem nenhum tipo de contrato ou direito social, característicos da "gig economy", uma forma gringa de dizer informalidade, nossa velha conhecida, já se contam aos milhões no país, com a pandemia multiplicando os serviços de delivery. O home office, que em tese flexibilizaria as jornadas de trabalho, tornam essas praticamente infinitas. Veja-se por exemplo o que está acontecendo com os professores de escola particulares que continuam com suas aulas a distância.

Esse "novo normal" vinculado às tecnologias informacionais esbarra em nossa extremada desigualdade social, o acesso a internet de banda larga o que impede, por exemplo, que as escolas e universidades públicas consigam efetivar o ensino a distância. Num país em que a maioria não tem acesso ao saneamento básico, habitação decente, transporte de qualidade, renda mínima, esperar grandes mudanças é muito otimismo. $\mathrm{O}$ crescimento da pandemia tem demonstrado que a desigualdade social é um fator de expansão geométrica. Como pedir isolamento social a quem vive num quarto com dez pessoas e que se "vira" diariamente para sobreviver? A classe média pode ficar em suas casas em quarentena e trabalhando em home office, mas para a maioria da população isso é quase um luxo.

$\mathrm{Na}$ política, a pandemia tem servido a realização de grandes negócios como a imprensa vem relatando. E isso entra na normalidade de nossa corrupção, do nosso estado patrimonialista - no caso o familismo é descarado - e no corporativismo do aparelho estatal. Este, objeto apenas de escândalo dos 
funcionários do executivo, da saúde-educação e da infra-estrutura administrativa. Exclui-se os altos salários e benesses variadas do judiciário, do legislativo em todos os níveis, e dos militares.

Mesmo sabendo que comparações históricas são sempre problemáticas, é assustador o avanço autoritário e a adesão das massas a esse discurso salvacionista, assim como a desarticulação de setores de oposição e da esquerda. A releitura da Psicologia de massas do Freud e outros textos escritos a cem anos atrás sobre a situação social e política europeia nos deixa preocupado quanto ao futuro. Pode parecer paradoxal, mas num mundo no qual a informação atinge praticamente toda a população, a desinformação sai vitoriosa. Grupos organizados a utilizam politicamente para reproduzir notícias falsas, as denominadas fakes news e espalhar a ignorância que atingem igualmente todas as classes sociais. E, no Brasil as fakes news se reproduzem a partir de atores políticos e instituições que multiplicam pânicos sociais, como por exemplo um "comunismo" comandado por demônios, ou saídas milagrosas da pandemia com feijões abençoados e vendidos em igrejas, vassouras benzidas, etc.

Esse quadro tem exigido da Sociologia, não apenas reler os clássicos, o que faz continuamente, mas ficar atenta a grupos sociais e temáticas que por muito tempo foram negligenciados. Não apenas as mudanças sociais, mas as tendências sociais conservantistas e as contradições e complementaridades entres essas tendências devem ser melhor estudadas se queremos entender o novo-velho mundo que se apresenta. Os tempos sombrios estão de volta e parafraseando Macalé (1971), não podemos ficar eternamente no porto vendo o movimentos dos barcos, mas temos que estar nesses barcos.

\section{Referências}

ELIAS, N. Conceitos sociológicos fundamentais. In NIEBURG, F; WAISBORT, L. (orgs), Norbert Elias, Escritos \& Ensaios 1. Rio de Janeiro: Jorge Zahar Editor, 2006.

FREUD, S.(2011[1921]) Psicologia das massas e análise do eu. In Sigmund Freud, Obras completas, vol 15. São Paulo: Cia das Letras, p.13-113, 2011.

MACALÉ, Jards (1971). Movimento dos barcos. Composição de José Capinan e Jards Silva. 
SCHWARTZ, L.M (2020). De perto ninguém é normal (ou o'novo normal'). Disponível em https://gamarevista.com.br/sociedade/de-perto-ninguem-e-normal-ou-onovo-normal/. Acesso em 22/05/2020.

Recebido: 07/12/2020

Aceito:13/12/2020 